\title{
Expression of P311, a transforming growth factor beta latency-associated protein-binding protein, in human kidneys with IgA nephropathy
}

\author{
Fengping Wang $\cdot$ Xisheng Xie $\cdot$ Junming Fan $\cdot$ \\ Li Wang • Dongyang Guo $\cdot$ Lichuan Yang • \\ Xiaofen Ma $\cdot$ Lina Zhang $\cdot \mathrm{Zi} \mathrm{Li}$
}

Received: 3 June 2009/Accepted: 5 November 2009/Published online: 28 November 2009

(C) The Author(s) 2009. This article is published with open access at Springerlink.com

\begin{abstract}
Background In cultured NIH3T3 cells, P311 binds to the transforming growth factor-beta (TGF- $\beta$ )-1 latency-associated protein (LAP) and induces the myofibroblast phenotype. In this study, we determined the levels of P311 and TGF- $\beta 1$ proteins in tubulointerstitial tissue of patients with different severities of immunoglobulin-A nephropathy (IgAN), and analyzed the relationships between $\mathrm{P} 311$ protein expression and clinical data.
\end{abstract}

F. Wang $\cdot$ X. Xie $\cdot$ J. Fan $(\bowtie) \cdot$ L. Yang

X. Ma - L. Zhang $\cdot$ Z. Li

Department of Nephrology, Sichuan University West

China Hospital, No. 37 Guoxue Xiang, 610041 Wu Hou

District, Chengdu, Sichuan Province, China

e-mail: junmingfan@163.com

F. Wang

e-mail:wfp2003@tom.com

J. Fan

State Key Laboratory of Biotherapy of Human Disease,

West China Hospital of Sichuan University, Chengdu,

China

L. Wang

Department of Nephrology, Sichuan Academy of Medical

Science \& Sichuan Provincial People's Hospital,

Chengdu, China

D. Guo

Department of Nephrology, Chengdu Military General

Hospital, Chengdu, China
Methods A total of 57 patients with IgAN and 5 controls (from partial nephrectomy) were included. P311 and TGF- $\beta 1$ protein expression were measured by immunohistochemistry and clinical data (proteinuria, serum creatinine (Scr), eGFR and biopsy index) were recorded. The relationship between P311, TGF$\beta 1$, and clinical data was analyzed.

Results P311 expression was significantly higher in the kidneys of IgAN patients than in controls and was higher in patients with advanced pathological grades of IgAN. P311 protein expression in tubulointerstitial tissue correlated with TGF- $\beta 1$ and proteinuria. P311 expression was higher in patients with $\mathrm{Scr}>$ $133 \mu \mathrm{mol} / \mathrm{L}$ than in patients with $\mathrm{Scr}<133 \mu \mathrm{mol} / \mathrm{L}$. Conclusion $\mathrm{P} 311$ protein expression in the kidneys of IgAN patients correlates with TGF- $\beta 1$ expression and with proteinuria. $\mathrm{P} 311$ might be a key cytokine in renal fibrosis and be involved in the progression of IgAN.

Keywords Clinical data - Immunoglobulin A nephropathy $\cdot$ P311 - Tubulointerstitial fibrosis . TGF- $\beta$ latency-associated protein

\section{Introduction}

Tubulointerstitial fibrosis, the loss of renal tubules and accumulation of extracellular matrix (ECM) proteins leads to end stage renal failure [1, 2]. 
Although tubular epithelial cells can synthesize numerous ECM proteins [3, 4], myofibroblasts are apparently the main sources of increased ECM deposition in renal fibrosis [4-6]. Previous studies have demonstrated that interstitial myofibroblasts derive from the differentiation of fibroblasts, migration of perivascular smooth muscle cells, or local proliferation [7-10]. Tubular epithelial cells can also transdifferentiate into myofibroblasts under pathological conditions, such as those present during tubulointerstitial fibrosis. TGF- $\beta 1$ is a key cytokine that regulates the progression of tubulointerstitial fibrosis [11].

The P311 protein, also known as the binding protein of TGF- $\beta$ LAP, is an $8-\mathrm{kD}$ protein originally found in neurons and muscle. A recent study showed that expression of P311 in NIH3T3 cells induced a myofibroblast phenotype with low TGF- $\beta 1$ expression [12]. Some researchers have suggested that P311 is involved in TGF- $\beta 1$-independent myofibroblast transformation and in the progression of fibrosis [13]. However, it is unknown whether P311 has a role in the progression of renal tubulointerstitial fibrosis, especially in IgA nepropathy (IgAN).

IgAN is the most common form of primary glomerulonephritis. Renal tubulointerstitial fibrosis is an important process in the progression of IgAN [14]. The pathogenesis of IgAN involves activation of mesangial cells and secretion of cytokines, such as TGF- $\beta 1$ and IL-1, which enhance cell proliferation, trans-differentiation, and accumulation of ECM, eventually leading to tubulointerstitial fibrosis [15]. However, no studies have examined the expression of P311 in tubulointerstitial tissue and the relationship of P311, TGF- $\beta 1$, and the clinical features of IgAN patients. In this study, we measured the expression of P311 and TGF- $\beta 1$ in biopsy samples of IgAN patients, and analyzed the relationship between these proteins and clinical data.

\section{Methods}

Patients and design

Fifty-seven $\operatorname{IgAN}$ patients were included in the present study. The diagnosis of primary IgAN was based on renal biopsy findings including a predominance of $\operatorname{IgA}$ deposits in the glomerular mesangial areas as detected by immunofluorescence. Patients with systemic disease such as Schönlein Henoch purpura, systemic lupus erythematosus, rheumatoid arthritis, diabetes mellitus, and liver cirrhosis were excluded. Five adult kidney tissues from partial nephrectomy for incidentaloma were included as controls.

The severity of pathological changes was graded according to Lee's classification [16, 17]. Grades I and II were considered as mild; grades III as moderate; grades IV and V as severe. The severity of tubulointerstitial lesions was graded according to the Katafuchi classification [18]. Cumulative score ranging from 1 to 3 was considered as mild (group I), cumulative score ranging from 4 to 6 as moderate (group II), and cumulative score ranging from 7 to 9 as severe (group III).

The severity of proteinuria was classified according to 24-h urine protein excretion: $<1 \mathrm{~g}$ as mild; $1-$ $3 \mathrm{~g}$ as moderate; $>3 \mathrm{~g}$ as severe. A patient with systolic blood pressure $>130 \mathrm{mmHg}$ or diastolic blood pressure $>80 \mathrm{mmHg}$ was considered hypertensive. Serum creatinine (Scr) level of $133 \mu \mathrm{mol} / \mathrm{L}$ was considered the upper normal limit. The equation developed by the MDRD Study Group was used to calculate eGFR [19]. Then, patients were divided into different subgroups (Scr $>133 \mu \mathrm{mol} / \mathrm{L}$ group vs. Scr $<133 \mu \mathrm{mol} / \mathrm{L}$; eGFR $<59 \mathrm{~mL} / \mathrm{min} / 1.73 \mathrm{~m}^{2}$ vs. eGFR $\geq 60 \mathrm{~mL} / \mathrm{min} / 1.73 \mathrm{~m}^{2}$ ). The Sichuan University Ethics Committee approved this study, and all participants gave informed consent.

Immunohistochemistry

Immunohistochemistry was performed on paraffinembedded tissue sections using polyclonal antibodies against P311 and TGF- $\beta 1$. Formalin-fixed, paraffinembedded tissue samples were examined. Sections ( $3 \mu \mathrm{m}$ thick) were mounted on polylysine-coated slides and deparaffinized. Antigen retrieval was performed by microwave heating for $4 \times 5 \mathrm{~min}$ cycles in a citrate buffer $(0.01 \mathrm{~mol} / \mathrm{L}, \mathrm{pH} 6.0)$. After washing with PBS, endogeneous peroxidase activity was blocked by incubating with $0.03 \% \mathrm{H}_{2} \mathrm{O}_{2}$ for $10 \mathrm{~min}$, and sections were washed with PBS again. Then sections were treated with $10 \%$ normal goat serum for $2 \mathrm{~h}$ and incubated overnight at $4{ }^{\circ} \mathrm{C}$ with anti-P311 polyclonal antibody (Biosynthesis Biotechnology, BIOS, China) or anti-TGF- $\beta 1$ polyclonal 
antibody (Santa Cruz Biotechnology, Santa Cruz, CA, USA). After washing with PBS, sections were incubated with HRP-labeled goat anti-rabbit P311 or TGF- $\beta 1$ antibodies (Biosynthesis Biotechnology, BIOS, China) for $1 \mathrm{~h}$. After washing again with PBS, sections were exposed to DAB for $15 \mathrm{~min}$, counterstained with Mayer's hematoxylin, and then mounted. We used single (no primary antibody) and double (no primary and no secondary antibody) negative controls. Red-brown granular cytoplasmic staining was considered as positive.

Statistical analysis

Image-Pro Plus 6.0 was used to analyze the immunostaining results. All data are presented as means \pm SDs. Statistical comparisons (correlation analysis, ANOVA, and Student's $t$-test) were performed with SPSS 13.0 software. The $r$ value represents the correlation coefficient based on Pearson's test, and a $P$ value less than 0.05 was considered significant.

\section{Results}

Clincal data

Kidney specimens from $57 \mathrm{IgAN}$ patients and five incidentaloma patients (controls) were analyzed.
According to Lee's pathological grading, specimens were classified as control, mild, moderate, or severe. Table 1 shows the clinical data of patients in these groups. ANOVA analysis indicated significant differences in proteinuria, eGFR, and Scr among these four groups $(P<0.05)$.

Based on Katafuchi pathological cumulative scores, kidney specimens were classified as control, group-I, group-II, or group-III. Table 2 shows the clinical data of patients in these groups. ANOVA analysis indicated significant differences in eGFR, Scr, and proteinuria among these four groups $(P<0.05)$.

\section{Expression of P311}

Immunohistochemical results indicated that $\mathrm{P} 311$ was not present in the renal interstitium of normal renal tissues (Fig. 1a). In other words, P311 is not normally expressed by the tubular epithelial cells and endothelial cells that line the glomerular and peritubular capillaries. In contrast, there was significant staining for P311 in the tubular epithelial cells of IgAN patients (Fig. 2a, b, c). There was a significant difference in the expression of P311 in normal and IgAN patients $(P<0.01)$. Interestingly, P311 was not detected in the renal glomerulus of IgAN patients or controls (Fig. 2d).

ANOVA analysis was performed for the four groups classified by Lee's pathological grading

Table 1 Relevant clinical data of subgroups according to Lee's pathological grading

\begin{tabular}{|c|c|c|c|c|}
\hline \multirow[t]{2}{*}{ Object } & \multirow[t]{2}{*}{ Control } & \multicolumn{3}{|c|}{ Lee's pathological grading } \\
\hline & & Mild & Moderate & Severe \\
\hline Number & 5 & 27 & 20 & 10 \\
\hline Age (years) & $33.00 \pm 6.29$ & $31.22 \pm 10.76$ & $39.40 \pm 13.96$ & $35.30 \pm 10.22$ \\
\hline Males/females & $1 / 4$ & $10 / 17$ & $11 / 9$ & $6 / 4$ \\
\hline Blood pressure systolic (mmHg) & $114.40 \pm 8.68$ & $110.09 \pm 35.19$ & $126.19 \pm 22.44$ & $134.15 \pm 23.66$ \\
\hline Blood pressure diastolic (mmHg) & $87.80 \pm 6.06$ & $71.99 \pm 25.62$ & $83.06 \pm 17.91$ & $87.60 \pm 18.58$ \\
\hline Proteinuria quantification (g per $24 \mathrm{~h}$ ) & $0.20 \pm 0.08$ & $2.72 \pm 2.33$ & $2.41 \pm 1.61^{\mathrm{a}}$ & $4.69 \pm 2.35^{\mathrm{a}, \mathrm{b}}$ \\
\hline Severe proteinuria rate $(\%)$ & 0 & 3.33 & 30.00 & 70.00 \\
\hline Serum creatinine $(\mu \mathrm{mol} / \mathrm{L})$ & $56.12 \pm 11.47$ & $92.63 \pm 49.42$ & $107.05 \pm 28.51^{\mathrm{a}}$ & $201.37 \pm 244.05^{\mathrm{a}, \mathrm{b}}$ \\
\hline Renal dysfuntion rate (\%) & 0 & 3.70 & 15.00 & 40.00 \\
\hline GFR (ml/min) & - & $81.84 \pm 32.46$ & $62.69 \pm 16.40^{\mathrm{a}}$ & $48.39 \pm 19.35^{\mathrm{a}, \mathrm{b}}$ \\
\hline
\end{tabular}

Expressed as mean $\pm \mathrm{SD}$

a Compared with mild group, $P<0.05$

b Compared with moderate group, $P<0.05$ 
Table 2 Relevant clinical data of subgroups according to Katafuchi pathological cumulative scores

\begin{tabular}{|c|c|c|c|c|}
\hline \multirow[t]{2}{*}{ Object } & \multirow[t]{2}{*}{ Control } & \multicolumn{3}{|c|}{ Katafuchi pathological cumulative scores } \\
\hline & & I & II & III \\
\hline Number & 5 & 33 & 19 & 5 \\
\hline Age (years) & $33.00 \pm 6.29$ & $31.55 \pm 10.92$ & $40.21 \pm 13.14$ & $35.80 \pm 12.13$ \\
\hline Males/females & $1 / 4$ & $13 / 20$ & $10 / 9$ & $4 / 1$ \\
\hline Blood pressure systolic (mmHg) & $114.40 \pm 8.68$ & $110.84 \pm 32.98$ & $130.04 \pm 21.48$ & $141.85 \pm 22.61$ \\
\hline Blood pressure diastolic (mmHg) & $86.80 \pm 6.06$ & $73.52 \pm 26.29$ & $85.74 \pm 12.64$ & $85.15 \pm 20.25$ \\
\hline Proteinuria quantification (g per $24 \mathrm{~h}$ ) & $0.20 \pm 0.08$ & $2.47 \pm 1.82$ & $3.24 \pm 2.15^{\mathrm{a}}$ & $5.06 \pm 3.78^{\mathrm{a}, \mathrm{b}}$ \\
\hline Severe proteinuria rate $(\%)$ & 0 & 30.30 & 42.11 & 80.00 \\
\hline Serum creatinine $(\mu \mathrm{mol} / \mathrm{L})$ & $56.12 \pm 11.47$ & $89.41 \pm 42.72$ & $113.98 \pm 28.14^{\mathrm{a}}$ & $307.92 \pm 325.57^{\mathrm{a}, \mathrm{b}}$ \\
\hline Renal dysfuntion rate $(\%)$ & 0 & 3.03 & 21.05 & 80.00 \\
\hline GFR (ml/min) & - & $81.96 \pm 28.63$ & $53.95 \pm 13.92^{\mathrm{a}}$ & $43.52 \pm 25.24^{\mathrm{a}, \mathrm{b}}$ \\
\hline
\end{tabular}

Expressed as mean $\pm \mathrm{SD}$

a Compared with mild group, $P<0.05$

b Compared with moderate group, $P<0.05$
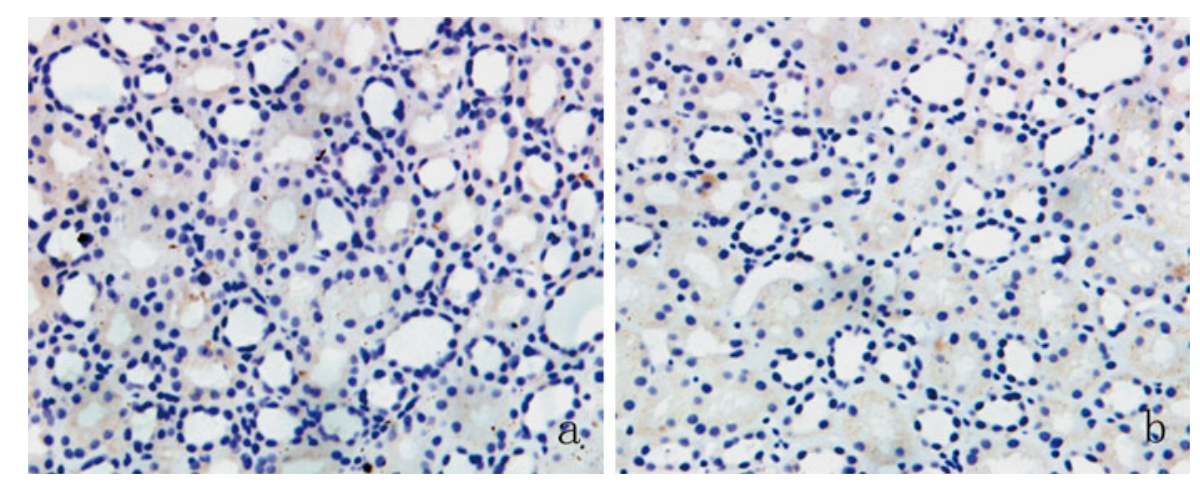

Fig. 1 Immunostaining of P311 (a) and TGF- $\beta 1$ (b) in normal renal tissues. Magnification: $\times 200$. Results are from representative sections of controls

(Table 3) and the four groups classified by Katafuchi pathological cumulative scores (Table 4). The results showed that the expression of P311 increased as the extent of tubulointerstitial fibrosis increased.

\section{Expression of TGF- $\beta 1$}

There was weak staining of TGF- $\beta 1$ in the interstitium of normal renal tissues (Fig. 1b) but significantly greater staining of TGF- $\beta 1$ in the interstitium of IgAN patients (Fig. 3a, b, c). TGF- $\beta 1$ was also present in the glomeruli of IgAN patients (Fig. 3d).

As mentioned earlier, ANOVA analysis was performed for the four groups classified by Lee's pathological grading (Table 3) and the four groups classified by Katafuchi pathological cumulative scores (Table 4). The results showed that expression of TGF- $\beta 1$ increased as the extent of tubulointerstitial fibrosis increased.

\section{Relationship between P311 and TGF- $\beta 1$ expression}

We also analyzed the relationship between the expression of P311 and TGF- $\beta 1$. Our results indicate that the expression of P311 correlated with the expression of TGF- $\beta 1(r=0.921, P<0.001)$ and that they had similar intracellular locations. 


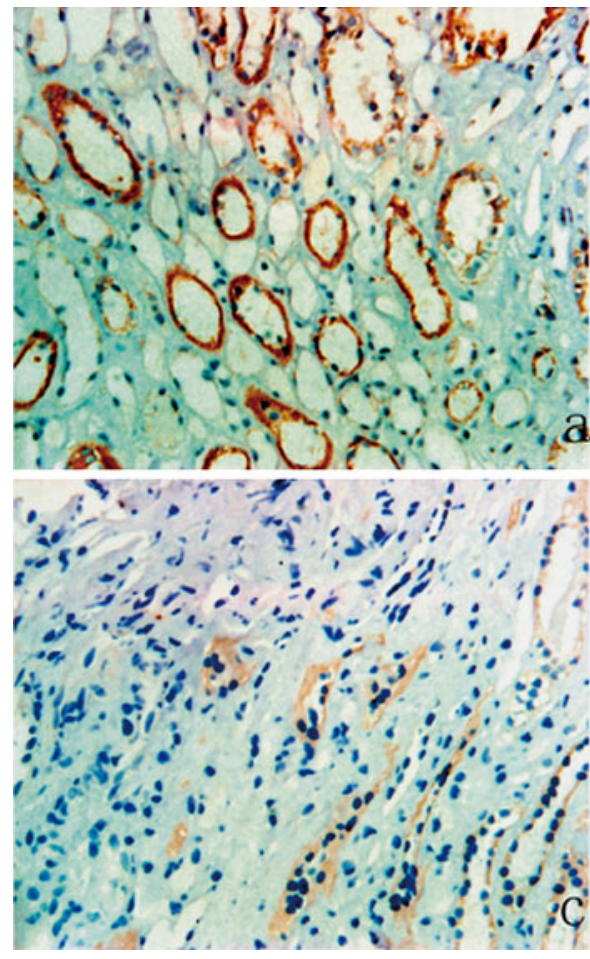

Fig. 2 Immunostaining of P311 in the renal tissues of patients with different grades of $\operatorname{IgA}$ nephropathy. Tubulointerstitial tissue of a patient from the (a) severe fibrosis group, (b) moderate fibrosis group, (c) mild fibrosis group, and the (d) renal glomerulus of a patient from IgAN. The staining of P311

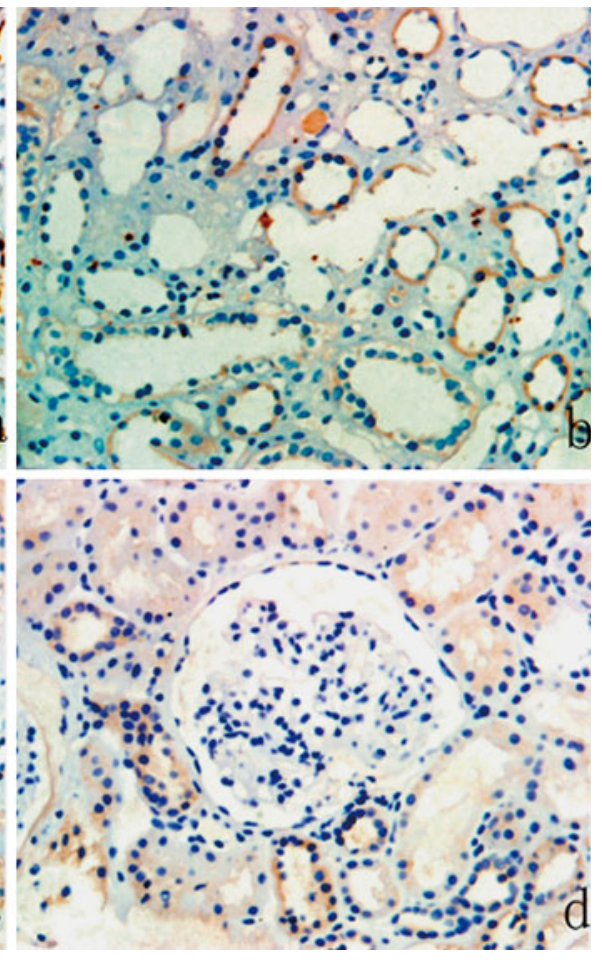

in tubular epithelial cells increases with the degree of tubulointerstitial fibrosis (a-c), but there is no P311 staining in renal glomerulus from $\operatorname{IgAN}(\mathbf{d})$. Magnification: $\times 200$. Results are from representative sections of different groups

Table 3 Expression of P311 and TGF- $\beta 1$ of subgroups according to Lee's pathological grading

\begin{tabular}{lllll}
\hline Object & Control $n=5$ & \multicolumn{4}{l}{ Lee's pathological grading } \\
\cline { 3 - 5 } & & Mild, $n=27$ & Moderate, $n=20$ & Severe, $n=10$ \\
\hline Score of staining intensity for P311 & 0 & $1.95 \pm 2.75$ & $5.00 \pm 7.86^{\mathrm{c}}$ & $20.09 \pm 15.78^{\mathrm{a}, \mathrm{b}}$ \\
Score of staining intensity for TGF- $\beta 1$ & $1.08 \pm 1.14$ & $2.42 \pm 3.21$ & $5.73 \pm 9.22^{\mathrm{c}}$ & $26.49 \pm 25.41^{\mathrm{a}, \mathrm{b}}$ \\
\hline
\end{tabular}

Expressed as mean $\pm \mathrm{SD}$

a Compared with mild group, $P<0.05$

b Compared with moderate group, $P<0.05$

c Compared with mild group, $P>0.05$

P311 expression and proteinuria

A total of 24 of 57 IgAN patients had severe proteinuria ( $>3 \mathrm{~g}$ per $24 \mathrm{~h}$ ), 24 had moderate proteinuria (1-3 g per $24 \mathrm{~h}$ ), and 9 had mild proteinuria $(<1$ g per $24 \mathrm{~h})$. ANOVA showed that P311 expression was higher as the severity of proteinuria increased (Table 5). In addition, there was a significant correlation between the amount of 24-h urine protein and P311 expression $(r=0.291, P<0.05)$.
P311 expression and serum creatinine

A total of 19 of 57 IgAN patients had renal dysfunction (Scr $>133 \mu \mathrm{mol} / \mathrm{L}$ ) before biopsy. The renal P311 expression in these patients was significantly higher than in the remaining $38 \mathrm{IgAN}$ patients $(14.59 \pm 15.01 \% \quad$ vs. $4.63 \pm 8.63 \%, \quad P<0.05)$. However, P311 expression was not significantly correlated with the level of serum creatinine ( $r=0.232, P>0.05)$. 
Table 4 Expression of P311 and TGF- $\beta 1$ of subgroups according to Katafuchi pathological cumulative scores

\begin{tabular}{lllll}
\hline Object & Control $n=5$ & \multicolumn{4}{l}{ Katafuchi pathological cumulative scores } \\
\cline { 3 - 5 } & & I, $n=33$ & II, $n=19$ & III, $n=5$ \\
\hline Score of staining intensity for P311 & 0 & $2.53 \pm 3.72$ & $7.58 \pm 12.48^{\mathrm{c}}$ & $25.23 \pm 11.40^{\mathrm{a}, \mathrm{b}}$ \\
Score of staining intensity for TGF- $\beta 1$ & $1.08 \pm 1.14$ & $4.23 \pm 9.52$ & $9.78 \pm 18.22^{\mathrm{c}}$ & $23.87 \pm 18.67^{\mathrm{a}, \mathrm{b}}$ \\
\hline
\end{tabular}

\footnotetext{
Expressed as mean $\pm \mathrm{SD}$

${ }^{\text {a }}$ Compared with group I, $P<0.05$

${ }^{\mathrm{b}}$ Compared with group II, $P<0.05$

c Compared with group I, $P>0.05$
}

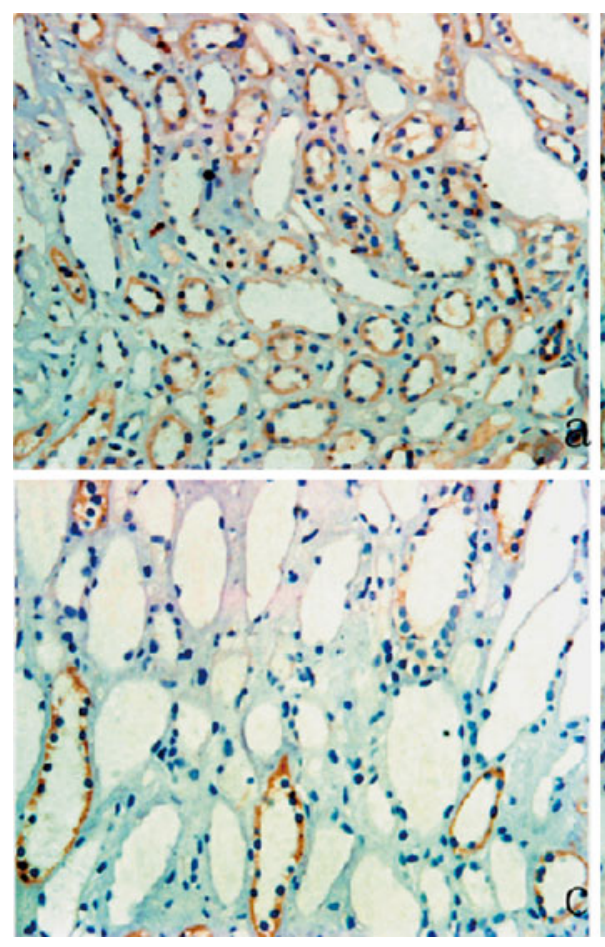

Fig. 3 Immunostaining of TGF- $\beta 1$ in the renal tissues of patients with IgA nephropathy. Tubulointerstitial tissue of a patient from the (a) severe fibrosis group, (b) moderate fibrosis group, (c) mild fibrosis group, and the (d) renal glomerulus of a patient from IgAN. As with P311 (Fig. 2), staining of TGF- $\beta 1$

\section{P311 expression and eGFR}

In the present study, 6 IgAN patients had eGFRs greater than $90 \mathrm{~mL} / \mathrm{min} / 1.73 \mathrm{~m}^{2}, 34$ patients had eGFRs of $60-89 \mathrm{~mL} / \mathrm{min} / 1.73 \mathrm{~m}^{2}, 15$ patients had eGFRs of $30-59 \mathrm{~mL} / \mathrm{min} / 1.73 \mathrm{~m}^{2}$, and 2 patients had eGFRs less than $29 \mathrm{~mL} / \mathrm{min} / 1.73 \mathrm{~m}^{2}$. We found that the mean level of $\mathrm{P} 311$ protein was higher in patients with eGFR $<59 \mathrm{~mL} / \mathrm{min} / 1.73 \mathrm{~m}^{2}$ than in those with

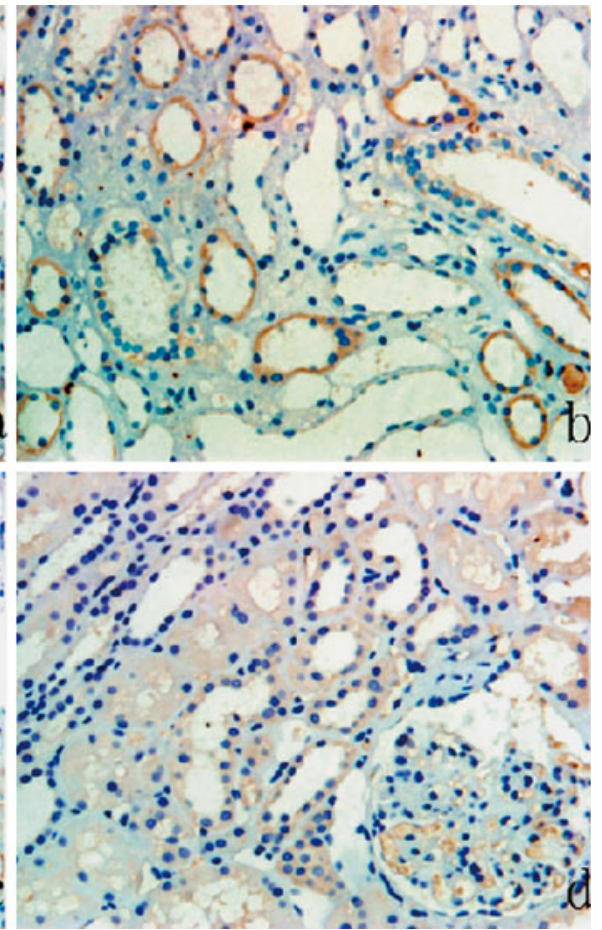

in tubular epithelial cells increases with the degree of tubulointerstitial fibrosis $(\mathbf{a}-\mathbf{c})$. There is weak TGF- $\beta 1$ staining in the renal glomerulus from $\operatorname{IgAN}(\mathbf{d})$. Magnification: $\times 200$. Results are from representative sections of different groups

eGFR $\geq 60 \mathrm{~mL} / \mathrm{min} / 1.73 \mathrm{~m}^{2}$, but this difference was not significant $(4.43 \pm 9.18 \%$ vs. $8.83 \pm 11.69 \%$, $P>0.05)$. P311 expression was not correlated with eGFR $(r=0.181, P>0.05)$.

P311 expression and other clinical data

A total of $14 \mathrm{IgAN}$ patients had hypertension before biopsy. A comparison of P311 expression in patients 
Table 5 Expression of P311 in different subgroups according to proteinuria severity

\begin{tabular}{lllll}
\hline Object & Control $n=5$ & \multicolumn{2}{l}{ Proteinuria severity } & \\
\cline { 3 - 4 } & & Mild, $n=33$ & Moderate, $n=19$ & Severe, $n=5$ \\
\hline Score of staining intensity for P311 & 0 & $2.73 \pm 3.36$ & \\
\hline Expressed as mean \pm SD & & \\
a Compared with mild group, $P<0.05$ & & \\
b Compared with moderate group, $P<0.05$ & \\
c Compared with mild group, $P>0.05$ &
\end{tabular}

with or without hypertension indicated a significant difference $\quad(12.74 \pm 14.82 \%$ vs. $4.09 \pm 8.82 \%$, $P<0.05)$. However, there was no significant correlation between P311 expression and blood pressure $(r=0.201, P>0.05)$. In addition, there was no significant correlation between P311 expression and patients age $(r=0.137, P>0.05)$.

\section{Discussion}

IgAN is the most common form of primary glomerulonephritis. The pathogenesis of IgAN involves activation of mesangial cells and secretion of cytokines such as TGF- $\beta 1$ and IL-1 [20, 21]. Tubular epithelial cells can transdifferentiate into myofibroblasts following stimulation by these cytokines, resulting in increased ECM deposition in tubulointerstitial tissue. The secretion of these cytokines, tubular epithelial myofibroblast trans-differentiation, and the accumulation of ECM eventually lead to tubulointerstitial fibrosis. In IgAN, tubulointerstitial fibrosis is considered to be the final pathway that leads to end stage renal failure [1]. Progressive renal insufficiency develops in about $40 \%$ of IgAN patients 25 or more years after initial diagnosis [15].

Numerous cytokines are involved in the progression of tubulointerstitial fibrosis [22], and TGF- $\beta 1$ is one of the most important cytokines controlling this process. There is a close relationship between the level of TGF- $\beta 1$ and the progression of tubulointerstitial fibrosis [11, 23]. TGF- $\beta 1$ promotes tubular epithelial myofibroblast trans-differentiation [11] and increases the synthesis and accumulation of ECM proteins [6].

TGF- $\beta 1$ is a multi-functional cytokine that is secreted within tissues as a biologically inactive complex with LAP. It becomes functionally active after extracellular modification. After post-translational processing, TGF- $\beta 1$ binds non-covalently to LAP to confer latency. The non-covalent interactions between TGF- $\beta 1$ and LAP can be disrupted in vitro by heat, extremes of $\mathrm{pH}$, and other chaotropic factors. However, in vivo, the disruption of the LAP and TGF- $\beta 1$ complex appears central to activation. Following the cleavage of LAP, the inactive latent complex of TGF- $\beta 1$ is converted into a mature functional protein. Several studies indicate that LAP may also be important in certain pathological processes. Zhang et al. showed that LAP can inhibit some TGF- $\beta 1$ signals that have a role in fibrosis [24]. A recent study found that LAP has chemotactic and anti-inflammatory activities that are independent of the presence of active TGF- $\beta 1$ [25].

$\mathrm{P} 311$ is an intracytoplasmic protein originally found in neurons and muscle that can bind to TGF$\beta$ LAP [12]. P311 does not belong to any established protein family, and its biological function remains largely unknown. In cultured NIH3T3 cells, P311 binds to LAP and induces a myofibroblast phenotype, upregulates $\alpha$-SMA, induces FGF-2, VEGF, and PDGF receptor, upregulates integrins $\alpha 3$ and $\alpha 5$, and increases cell proliferation [12]. The in vitro P311-mediated changes differ from the well-characterized myofibroblast trans-differentiation, in that P311 inhibits the expression of TGF- $\beta 1$ and TGF$\beta 2$ [13]. These results suggested P311 is involved in the progression of fibrosis, but it is unknown whether P311 is also involved in the progression of renal tubulointerstitial fibrosis, especially in the kidneys of IgAN patients.

Heretofore, no studies have examined whether P311 is expressed in the tubulointerstitial tissue of IgAN patients, and there are no reports on the relationship between P311, TGF- $\beta 1$, and clinical data of patients with IgAN. 
Our study shows that expression of P311 in the kidneys of $\operatorname{IgAN}$ patients was significantly higher than in normal controls. In addition, greater expression of P311 was present in the kidneys of patients with more advanced tubulointerstitial fibrosis. The mechanism of P311 upregulation in the tubulointerstitial tissues of IgAN patients remains unknown. In the early stages of IgAN, a patient is in a proinflammatory state, so this is one possible reason for P311 upregulation.

The expression of TGF- $\beta 1$ was also elevated in the kidneys of IgAN patients. Interestingly, the expression of P311 correlated with the expression of TGF$\beta 1$, and both occurred at similar locations within cells. It has been demonstrated previously that TGF$\beta 1$ is a key mediator in renal fibrotic progression [11, $23]$. In the present study, our results suggest that P311 and TGF- $\beta 1$ may bind to one another and thereby induce tubulointerstitial fibrosis in patients with IgAN.

In the early stages of $\operatorname{IgAN}$, the patient is in a proinflammatory state, resulting in cell proliferation and secretion of cytokines such as TGF- $\beta$, IL- 1 , and CTGF. At the same time, the proinflammatory state induces upregulation of P311. Considering that P311 binds to TGF- $\beta 1$ LAP, it may contribute to the progression of tubulointerstitial fibrosis by several mechanisms. One possibility is that P311 binds to TGF- $\beta 1$ LAP, changes the conformation of LAP, and depresses LAP function. LAP bound to P311 could not inhibit TGF- $\beta 1$ signals that result in fibrosis, and could not block inflammation. Thus, LAP bound to P311 would facilitate inflammation and fibrosis. Another possibility is that elevation of P311 contributes to activation of latent TGF- $\beta 1$. Integrins are crucial for the activation of latent TGF- $\beta 1$ [26] and elevated P311 induces upregulation of $\alpha$-SMA, induction of integrins, and increased cell proliferation [12], which promotes the activation of latent TGF- $\beta 1$. The active form of TGF- $\beta 1$ promotes tubular epithelial myofibroblast trans-differentiation, enhances the synthesis of ECM proteins, and leads to tubulointerstitial fibrosis.

A second important finding in this study is that there was a correlation of $\mathrm{P} 311$ expression with various clinical parameters. Among our IgAN patients, there was a significant correlation between 24-h proteinuria and expression of $\mathrm{P} 311$, and between P311 expression and extent of tubulointerstitial fibrosis. This suggests that P311 might be involved in the progression of IgAN. Although the expression of P311 in patients with $\mathrm{Scr}>133 \mu \mathrm{mol} / \mathrm{L}$ was significantly higher than in patients with $\mathrm{Scr}<$ $133 \mu \mathrm{mol} / \mathrm{L}$ and normal controls, P311 expression was not correlated with eGFR or Scr. This study also showed that expression of P311 and TGF- $\beta 1$ in tubulointerstitial tissue from IgAN patients was higher than that of control patients, and that expression of these two proteins correlated with various clinical parameters and kidney lesion classification.

Finally, there is no indication that our findings would be specific for patients with $\operatorname{IgAN}$. In fact, P311 expression may also be induced in the kidneys of patients with other renal diseases or renal damage, such as acute tubular necrosis or lupus nephritis. Studies are currently in progress to measure the expression of P311 in patients with other kidney impairments and to identify the role of P311 in the pathogenesis of IgAN.

Conflict of interest statement We have had no involvements that might raise the question of bias in the work reported or in the conclusions, implications, or opinions stated. The results presented in this paper have not been published previously in whole or part.

Open Access This article is distributed under the terms of the Creative Commons Attribution Noncommercial License which permits any noncommercial use, distribution, and reproduction in any medium, provided the original author(s) and source are credited.

\section{References}

1. Eddy AA (1996) Molecular insights into renal interstitial fibrosis. J Am Soc Nephrol 7:2495-2508

2. Kiichiro J, David J, Lan HY et al (2001) Tubular phenotypic change in progressive tubulointerstitial fibrosis in human glomerulonephritis. Am J Kidney Dis 38:761-769

3. Tang W, Van G, Qi M (1997) Myofibroblast and $\alpha_{1}$ (III) collagen expression in experimental tubulointerstitial nephritis. Kidney Int 51:926-931

4. Stauart G, Kimberley M, Aled O (2001) Regulation of renal proximal tubular epithelial cell fibroblast growth factor 2 generation by heparin. Am J Kidney Dis 38:597609

5. Zhang HY, Gharaee Kermani M, Zhang K et al (1996) Lung fibroblast alpha smooth muscle actin expression and contractile phenotype in bleomycin induced pulmonary fibrosis. Am J Pathol 148:527-537

6. Ponda M, Siconolfi L, Kopp J (2007) NAGL and Extracellular Matrix Proteins in TGF- $\beta$ induced chronic renal fibrosis. Am J Kidney Dis 49:B66 
7. Hewitson TD, Wu H, Becker G (1995) Interstitial myofibroblasts in experimental renal infection and scarring. Am J Nephrol 15:411-417

8. Desmouliere A, Gabbiani G (1995) Myofibroblast differentiation during fibrosis. Exp Nephrol 3:134-139

9. Masur SK, Dewal HS, Dinh TT et al (1996) Myofibroblasts differentiate from fibroblasts when plated at low density. Proc Natl Acad Sci USA 93:4219-4223

10. Tang WW, Ulich TR, Lacey DL et al (1996) Platelet derived growth factor BB induces renal tubulointerstitial myofibroblast formation and tubulointerstitial fibrosis. Am J Pathol 148:1169-1180

11. JunMing F, YeeYung N, Prudence A et al (1999) Transforming growth factor $\beta$ regulates tubular epithelial myofibroblast transdifferentiation in vitro. Kidney Int 56:14551471

12. Seema P, Jinghua S, Urimil D et al (2004) P311 binds to the latency associated protein and downregulates the expression of TGF- $\beta 1$ and TGF- $\beta 2$. Biochem Bioph Res Co 315:1104-1109

13. Pan D, Zhe X, Jakkaraju S et al (2002) P311 induces a TGF- $\beta 1$ independent, nonfibrogenic myofibroblast phenotype. J Clin Invest 110(9):1349-1358

14. Chauveau D, Droz D et al (1993) Follow up evalution of the first patients with IgA nephropathy described at Necker Hospital. Contrib Nephrol 104:1-5

15. D'amico G (1987) The commonest glomerulonephritis in the world:IgA nephropathy. Quart J Med 64:709-727

16. Lee SM (1997) Prognostic indicators of progressive renal disease in IgA nephropathy: emergence of a new histologic grading system. Am J Kidney Dis 29:953-958

17. Haas M (1997) Histologic subclassification of $\operatorname{IgA}$ nephropathy: a clinicopathologic study of 244 cases. Am J Kidney Dis 29:829-842
18. Katafuchi R, Kiyoshi Y, Oh Y (1998) Glomerular score as prognosticator in $\operatorname{IgA}$ nephropathy: its usefulness and limitation. Clin Nephrol 49:1-8

19. Levey AS, Bosch JP, Lewis JB et al (1999) A more accurate method to estimate glomerular filtration rate from serum creatinine: A new prediction equation. Ann Intern Med 130:461-470

20. Toyoda M, Suzuki D, Uimezono T et al (2002) High expression of connective tissue growth factor mRNA is an important factor in the pathogenesis of human IgA nephropathy. Nephrology 7:116-117

21. Angela MD, Francis WB (2006) Mesangial autoantigens in IgA nephropathy: matrix synthesis and localization. J Lab Clin Med 147:301-309

22. Iwano M, Neilson EG et al (2004) Mechanisms of tubulointerstitial fibrosis. Curr Opin Nephrol Hypertens 13(3): 279-284

23. Sato M, Muragaki Y, Saika S et al (2003) Targeted disruption of TGF- $\beta 1 / \mathrm{Smad} 3$ signaling protects against renal tubulointerstitial fibrosis induced by unilateral ureteral obstruction. J Clin Invest 112:1486-1494

24. Zhang Y, McCormick LL, Gilliam AC (2003) Latencyassociated peptide prevents skin fibrosis in murine sclerodermatous graft-versus-host disease, a model for human scleroderma. J Invest Dermatol 121:713-719

25. Naeem AA, Alice AG, Charles GO et al (2008) Latency Associated Peptide Has In Vitro and In Vivo Immune Effects Independent of TGF- $\beta 1$. PloS ONE 3:e1914. doi: 10.1371/journal.pone.0001914

26. Pierre Jean W, Boris $H$ (2008) Integrins and the activation of latent transforming growth factor $\beta 1$-An intimate relationship. Eur J Cell Biol 87:601-615 